\title{
Fronteiras dos discursos audiovisuais sobre o jovem em conflito com a lei
}

\section{Frontiers of audiovisual discourses on young people in conflict with the law}

Caio Túlio Padula Lamas ${ }^{1}$ 


\section{Resumo}

O artigo tem por finalidade apresentar dados contextuais, pressupostos teóricos e algumas análises iniciais de pesquisa de doutorado em desenvolvimento na Universidade de São Paulo. A partir da análise do longa-metragem De menor (2013) e da websérie O filho dos outros (2017), procura-se encontrar convergências entre narrativas audiovisuais de diferentes gêneros e mídias com o intuito de melhor oferecer subsídios ao estudo de representações de jovens em conflito com a lei na cultura audiovisual. Conclui-se que ambas as produções estabelecem uma crítica ao sistema de justiça, além de tensionar os estereótipos de jovens autores de ato infracionais.

Palavras-chave

Discurso, mídias, jovem em conflito com a lei, estigma, estereótipo.

\section{Abstract}

The article aims to present contextual data, theoretical assumptions and some initial analyses of an in-development PhD research at University of São Paulo. From the analysis of the feature film De menor (2013) and the web series $O$ filho dos outros (2017), it is sought to find convergences between audiovisual narratives of different genres and media in order to better offer subsidies to the study of depictions of young people in conflict with the law in audiovisual culture. It was concluded that both productions establish a critique of the justice system, in addition to stressing the stereotypes of young offenders.

\section{Keywords}

Discourse, media, young people in conflict with the law, stigma, stereotype. 
Brasília, 27 de junho de 2019. Acontece no Senado um debate a respeito de uma proposta de emenda constitucional (PEC 115/2015) que prevê a redução da maioridade penal de 18 para 16 anos em casos de crimes hediondos, homicídio doloso e lesão corporal seguida de morte. Na ocasião, a advogada Marisa Rita Riello Deppman, cujo filho de 19 anos foi morto por um jovem de 17, declarou:

Direitos humanos é para humanos direitos. É para mim também. Tortura foi ter que ir ao IML liberar o corpo do meu filho para o enterro. Já estive no Congresso em 2013 e falei a mesma coisa: os legisladores vivem numa ilha da fantasia, mas precisam lembrar que menores matam, e matam com requintes de crueldade [...]. (GUEDES, 2019, s.p.)

As palavras de Marisa são bastante sintomáticas de um debate que volta a surgir na esfera pública brasileira depois do atentado à escola Raul Brasil, em Suzano, no qual 8 pessoas foram mortas e 11 ficaram feridas por 2 ex-alunos da instituição, um deles de 17 anos (LIRA, 2019). Na ocasião, a redução da maioridade penal foi defendida publicamente por senadores como Flávio Bolsonaro (PSL-RJ) e Major Olímpio (PSL-SP), em posição semelhante à defendida pelo então candidato Jair Bolsonaro durante a disputa presidencial de 2018. Dentro dessa perspectiva, a redução aparece como solução rápida para uma situação que não apresenta perspectiva de melhoras.

Segundo o Atlas da Violência 2018, documento formulado pelo Instituto de Pesquisa Econômica Aplicada (IPEA)² e pelo Fórum Brasileiro de Segurança Pública (FBSP) para a compreensão da violência no Brasil, 62.517 pessoas foram mortas por homicídio no país somente no ano de 2016 . O relatório registra que, no período de 2006 a 2016, houve um aumento de 25,8\% na quantidade total desse tipo de crime, com destaque sobretudo às regiões Norte e Nordeste.

Tais dados são ainda mais graves quando consideramos o fator raça: segundo o Atlas, enquanto a taxa de homicídios de não-negros ${ }^{3}$ em 2016 era de 
$16 \%$, a de negros ${ }^{4}$ era $40,2 \%$, em uma diferença de duas vezes e meia que aponta como negros e brancos vivem em países diferentes no quesito segurança pública.

O documento, entretanto, revela também dados geralmente ocultos nas inflamadas posições favoráveis à diminuição da maioridade penal. Os jovens compõem um dos grupos sociais que mais sofrem com a violência no país: somente no ano de 2016, 33.590 pessoas de 15 a 29 anos foram vítimas de homicídios em todo o território nacional, ponto culminante de uma tendência crescente desde 2006, ano em que as estatísticas começaram a ser mensuradas ${ }^{5}$. A situação é particularmente dramática em estados como o Rio Grande do Norte, que registrou aumento de 382,2\% de 2006 a 2016, entre outros estados da região Nordeste e Norte do país ${ }^{6}$.

Ao mesmo tempo, dados do Conselho Nacional de Justiça (CNJ) apontam a internação de 22.203 jovens nas 461 unidades socioeducativas de todo o país, 7.911 somente no estado de São Paulo7. Embora não haja, por parte do CNJ, dados precisos da distribuição dos tipos de infração cometidos, é possível supor que ao menos parcela desses jovens foi internada por pequenos delitos como furtos e roubos, o que leva à constatação de que jovens são geralmente as principais vítimas da violência no país, e não seus algozes.

Nada disso impede, entretanto, que a redução da maioridade penal seja defendida por amplos setores da sociedade: segundo pesquisa do Datafolha divulgada em janeiro de 2019 (DATAFOLHA..., 2019) ${ }^{8}$, 84\% das pessoas que responderam ao questionário são favoráveis à redução de 18 para 16 anos. Ao mesmo tempo, $67 \%$ dos interrogados opinaram pela redução para qualquer 
tipo de infração, sem a necessidade de especificar quais seriam consideradas mais graves e passíveis de punição mais rigorosa.

Todo o quadro acima delineado motiva minha pesquisa de doutorado na Universidade de São Paulo, na qual estabeleço como foco as inter-relações dos discursos sobre os jovens em conflito com a lei presentes na cultura audiovisual, tomando como objetos específicos de estudo filmes, programas de televisão e vídeos lançados e exibidos a partir do ano de 2002 que tematizem o jovem autor de ato infracional ${ }^{9}$.

Parto do princípio de que os discursos, longe de serem meramente reflexos de um mundo que Ihes seria externo e concreto, constroem eles próprios a realidade social, estabelecendo enquadramentos, divisões e hierarquias sobre os objetos, sujeitos e acontecimentos. Dentro dessa perspectiva, entendo que a crítica dos discursos midiáticos deve levar em consideração necessariamente o forte elemento relacional que está presente em suas materialidades, evidenciando as complementariedades e embates que acontecem ao longo das conjunturas históricas. Parto, igualmente, da premissa de que os discursos veiculados nas mídias, em especial na televisão, são em sua maioria unívocos em circunscrever o jovem autor de ato infracional sob a condição do adolescente de identidade de gênero masculino, negro, pobre, violento e impune, caracterizando, assim, um estigma consolidado na cultura.

O conceito de estigma, aqui, é entendido a partir da perspectiva de Goffman (1978): uma característica depreciativa atribuída a determinado grupo social, reduzindo os sujeitos que o compõem e retirando-lhes outras características que os tornariam seres humanos completos. Assim, um jovem internado em instituição socioeducativa não é mais um ser humano com medos, desejos, anseios e frustrações, mas tão somente um ser violento e incontrolável a quem caberia aplicar medidas disciplinares e de restrição de liberdade. 
É importante observar que, segundo o autor, nem todos os atributos indesejáveis podem ser considerados estigmas, somente aqueles que provocam uma tensão entre a identidade social virtual - expectativas que construímos de determinadas categorias sociais - e a identidade social real - atributos reais da pessoa a que fazemos referência. Diversas são as imagens que constituem a identidade social virtual e que circulam nas mídias, razão pela qual a análise delas se mostra fundamental para a desconstrução de estigmas em certas configurações históricas e sociais.

Há que se destacar, ainda, como os estigmas apresentam um forte elemento relacional:

O termo estigma será usado em referência a um atributo profundamente depreciativo, mas o que é preciso, na realidade, é uma linguagem de relações e não de atributos. Um atributo que estigmatiza alguém pode confirmar a normalidade de outrem, portanto ele não é, em si mesmo, nem honroso nem desonroso. (GOFFMAN, 1978, p. 13)

Assim, só há o estigma do criminoso e do preso porque há outros sujeitos que, ao contrário, preenchem certas expectativas sociais, nesse caso marcadas por questões de raça e classe. Diante desse quadro, busco compreender quais são os discursos audiovisuais menos estigmatizantes sobre os jovens em conflito com a lei presentes nas mídias e de que forma eles se inter-relacionam. Entre os objetivos, procuro identificar possíveis fissuras do estereótipo do adolescente autor de atos infracionais, em quais momentos e obras elas ocorrem e que outras representações foram propostas em seu lugar.

A reflexão que exponho neste artigo é parte das análises ainda em andamento. Levando em consideração a diversidade de mídias e gêneros sobre os quais me debruço, analiso o longa-metragem De menor (2014) e a websérie O filho dos outros (2017), ambas produções que propõem outras formas de representação de jovens em conflito com a lei. 


\section{Estereótipos, estigmas e os termos do debate}

Entretanto, antes de expor as análises, julgo fundamental tecer algumas considerações a respeito dos termos empregados no debate sobre a redução da maioridade penal. Se nos atentarmos novamente para o depoimento da advogada Marisa Rita Riello Deppman, transcrito no início do artigo, percebemos o uso da palavra menor para designar os jovens que matam com requintes de crueldade.

Tal termo, amplamente utilizados pelas mídias, já se encontra na letra da lei desde a primeira metade do século XIX, quando há registros de discursos cujo foco recai sobre crianças e adolescentes que porventura tivessem infringido leis e que pertencessem a segmentos marginalizados da sociedade brasileira. Juristas, médicos, governantes, jornalistas, ativistas, psicólogos, acadêmicos, entre outros, disputam a partir de qual terminologia deve-se fazer referência a tal grupo social.

De acordo com Marino (2013), o menor aparece pela primeira vez na legislação nacional no Código Criminal do Império do Brasil, de 1830. Tal denominação nasceu por conta da necessidade de institucionalizar punições a crianças e adolescentes pobres que violassem a lei, em número crescente nos centros urbanos. Na ocasião, vigorou no meio jurídico a denominada Teoria da ação com discernimento: se o juiz considerasse que a criança e o adolescente, mesmo se fosse menor de 14 anos, tivessem agido com discernimento, seriam responsabilizadas tal como um adulto e enviadas para as chamadas casas de correção.

A arbitrariedade é evidente. Por correção é possível inferir que todos aqueles que adentravam nessas instituições eram sujeitos errados, incorretos, que precisariam ser corrigidos para alcançar o mesmo patamar de civilidade que os demais. E tal denominação era feita exclusivamente pelo juiz: sua palavra tinha o poder de restringir ou não a liberdade de crianças e adolescentes apreendidos pela polícia.

Esta terminologia percorreu todo o século XIX e grande parte do XX, dando nome a diferentes instituições e legislações específicas: o Serviço de Atendimento ao Menor (SAM), criado em 1941, que seria substituído a partir 
dos anos 1960 pela Fundação Nacional do Bem-Estar do Menor (Funabem) e pelas Fundações Estaduais do Bem-Estar do Menor (Febens); os dois Códigos de Menores do Brasil, que seriam promulgados em 1927 e 1979; entre outras instituições e códigos jurídicos.

Ao longo de todo esse período, a lei não cessou de reenquadrar essa categoria, acrescentando-Ihe outras divisões ou aplicando-Ihe formas específicas de sanções. Se a categoria do menor, em um primeiro momento, estava diretamente relacionada à necessidade de punição à crescente quantidade de crianças e adolescentes que perambulava abandonadas pelas ruas da cidade, em um segundo estágio a preocupação se tornou a manutenção da ordem e do progresso nacionais, entendidos sob a perspectiva de uma racionalidade científica que transformava em patologia tudo aquilo que estivesse fora de uma norma social considerada aceitável.

Nasce dentro dessa perspectiva a concepção da criança enquanto futuro da nação. Em oposição a essa criança idealizada, dissemina-se no início do século $\mathrm{XX}$ aquelas denominadas de pivettes, "responsáveis pelos furtos e vadiagens que assolavam os centros urbanos" (MARINO, 2013, p. 66) A quantidade desse tipo de infração foi tamanha que, segundo Marino, o número de prisões entre menores e maiores de idade era praticamente equivalente entre 1900 e 1916.

Posteriormente, em 1923, é aprovado o Regulamento de Assistência e Proteção aos Menores Abandonados e Delinquentes. Tal código jurídico, ao trazer já em seu nome o termo delinquentes, evoca um jovem que "se distingue do infrator pelo fato de não ser tanto seu ato quanto sua vida o que mais o caracteriza" (FOUCAULT, 1987, p. 211 apud MARINO, 2013, p. 78). Tal denominação, altamente estigmatizante, foi adotada no primeiro Código de Menores do Brasil, de 1927, no qual se entendia que uma família desestruturada seria a grande causa das infrações juvenis e que caberia ao Estado, de forma flagrantemente autoritária, buscar recuperar o estatuto de civilidade a crianças e adolescentes nessa situação. 
Com o golpe militar de 1964 , esses jovens seriam enquadrados dentro da concepção vigente na época pelo Estado: não mais sujeitos anormais, impeditivos da manutenção da ordem e progresso sociais, mas inimigos internos da nação, inseridos em uma concepção bélica dos conflitos sociais, aos quais caberiam todas as formas possíveis de correção, dessa vez dentro dos muros das unidades da Funabem e, posteriormente, das Febems.

Em toda essa trajetória, há uma ligação profunda entre pobreza e periculosidade, e uma oposição inevitável entre o "menorismo" e a infância. Somente determinadas pessoas poderiam ser denominadas crianças, com todas as implicações sociais que isso poderia acarretar. Se a elas é facultado o direito de usufruir uma fase peculiar da vida, aos menores nada mais compete a não ser a correção e formas de disciplina que, no mais das vezes, convergiam para a prática de trabalhos domésticos ou forçados. O trabalho era visto frequentemente como uma prática pedagógica, via de acesso a uma cidadania nunca plena, pois incompatível com discursos estigmatizantes que atravessavam o corpo e a fala de sujeitos desprivilegiados ${ }^{10}$.

Tal quadro delineado forma também estereótipos de quem seriam esses menores, entendidos a partir da concepção sugerida por Mazzara (1999) e Lippmann (2017): formas rígidas a partir das quais vemos os objetos, sujeitos e acontecimentos do mundo.

Tal sentido para o termo foi consolidado a partir de 1922, com a publicação de Opinião Pública, livro do jornalista estadunidense Walter Lippmann, que se tornou referência no campo da Comunicação e das Ciências Sociais. Partindo de algumas observações ligadas ao contexto do fim da Primeira Guerra Mundial, Lippmann identificou os estereótipos como parte fundante de nossa percepção. São eles que permitem estabelecer critérios de distinção e estabilidade em um mundo caótico e desafiador:

10 Não à toa, é possível estabelecer comparações entre a situação desses jovens e a escravidão que, para o sociólogo Jessé Souza (2017), seria o componente mais intrínseco da formação da sociedade brasileira. 
Na maior parte dos casos nós não vemos em primeiro lugar, para então definir, nós definimos primeiro e então vemos. Na confusão brilhante, ruidosa do mundo exterior, pegamos o que nossa cultura já definiu para nós, e tendemos a perceber aquilo que captamos na forma estereotipada para nós por nossa cultura. (LIPPMANN, 2017, p. 92)

Esse seria o porquê, segundo o autor, pessoas comumente só se recordem de uma paisagem se esta for semelhante àquela presente na pintura pendurada em suas salas de estar. Ou a razão porque, em uma simples descrição de uma briga observada momentos antes, os relatos sejam em grande parte imprecisos ou com elementos que não estavam presentes na ocasião. Um simples relato, que em teoria deveria apresentar dados e constatações, frequentemente transfigura os acontecimentos a partir de estereótipos fornecidos pela mídia, pela arte, por códigos morais e grupos sociais específicos.

Longe de serem abstratos e pouco impactantes, os estereótipos orientam de forma concreta nossa ação no mundo. Atos de discriminação e exclusão, como também de acolhimento e inclusão, são baseados nas imagens que criamos a partir de ideias de objetos, sujeitos e acontecimentos. Mazzara chega a destacar a relação íntima que os estereótipos têm com os preconceitos. O estereótipo

\begin{abstract}
na prática constitui o que poderíamos chamar de um núcleo cognitivo do preconceito, ou seja, um conjunto das informações e crenças a respeito de uma certa categoria de objetos, reelabora em uma imagem coerente e constante, em condição de sustentar e reproduzir o preconceito em relação a eles. (MAZZARA, 1999, p. 14) $)^{11}$
\end{abstract}

Desse modo, o preconceito, entendido como "tendência a pensar (e atuar) de forma desfavorável diante de um grupo" (MAZZARA, 1999, p. 16) ${ }^{12}$, embasa ações concretas de dominação e violência aplicadas, sobretudo, a segmentos sociais estigmatizados. Mobilizam-se, assim, a partir das terminologias do "menorismo",

11 No original: "en la práctica constituye lo que podríamos llamar el núcleo cognitivo del prejuicio, es decir, el conjunto de las informaciones y creencias respecto a una cierta categoría de objetos, reelaborada en una imagen coherente y tendencialmente constante, en condición de sostener y reproducir el prejuicio frente a ellos". 
uma série de estereótipos sobre os jovens até então denominados como menores que, no mais das vezes, tendem a se concentrar em meninos pobres, negros, violentos e perigosos, e que estão na base da formação do estigma do menor infrator tal como consolidado na cultura.

Essa trajetória de consolidação do estereótipo do menor sofreu um ponto de inflexão a partir de meados do século $X X$, com o surgimento de um outro conjunto de palavras para designar esse tipo de sujeito. A infância ganha destaque internacional com a Declaração dos Direitos da Criança, de 1959, já sob influência da Declaração Universal dos Direitos Humanos, de 1948. Com a promulgação da Constituição Federal de 1988, foram abandonados os termos menor, com o emprego da chamada Doutrina da Proteção Integral e a prioridade absoluta que deveria ser dada a crianças e adolescentes, dessa vez considerados sujeitos de direitos e deveres, independente de classe social, etnia, gênero ou credo.

Inspirado pela nova Constituição, é promulgado o Estatuto da Criança e do Adolescente (ECA) em 1990, ratificando e ampliando alguns de seus princípios. Crianças e adolescentes, a partir daí, não poderiam sofrer qualquer forma de "negligência, discriminação, exploração, violência, crueldade e opressão, tendo em vista sua condição peculiar de pessoa em desenvolvimento" (MARINO, 2013, p. 74).

A partir desse contexto, passa a surgir a chamada nova filantropia, exercida por organizações não governamentais, e há a proliferação de outras terminologias para designar esses jovens. Assim, o Manual comunicação e direitos humanos: infância e juventude em pauta, formulado pelo Instituto Terre des Hommes Brasil, enfatiza como, em vez de adotar termos como delinquente, criminoso ou marginal, a imprensa deveria utilizar adolescente em conflito com a lei, jovem em conflito com a lei ou acusado de ter cometido ato infracional. Segundo o manual, 
superadas. "Em conflito com a lei" estabelece uma condição temporal e superável. O adolescente não "é". Ele "está". (INSTITUTO TERRE DES HOMMES BRASIL, 2019, p. 64)

De forma semelhante, o manual reitera como o termo menor deve ser evitado, substituindo-o por crianças e adolescentes, e mesmo a palavra crime estaria equivocada - tratar-se-ia de ato infracional, infração ou delito, uma vez que tais palavras subentendem que os jovens são sujeitos em desenvolvimento e, portanto, teriam a oportunidade de aprender com os próprios erros.

Tal terminologia, entretanto, não deixa de ser controversa. Isso porque é possível inferir, a partir de jovem em conflito com a lei, que algo permanece incontestável: a lei. Caberia ao jovem, inevitavelmente, adaptar-se a ela sem qualquer tipo de questionamento. Se entendermos que leis são discursos que, da mesma forma que outros, estão inseridos em relações de poder em determinadas conjunturas históricas, é inevitável presumir de que cabe sim o seu questionamento, de acordo com outros parâmetros de ética e justiça que poderiam ser levantados e problematizados.

Jovem em situação de vulnerabilidade social, presente igualmente em textos acadêmicos e ativistas ${ }^{13}$, poderia ser uma alternativa que, entretanto, parece ser genérica, sem se atentar às especificidades de jovens que tenham cometido infrações e incluindo-os na mesma categoria de outros que vivem em condições sociais periféricas. Razão pela qual priorizo a terminologia jovem em conflito com a lei, sem negar com isso seus limites.

\section{De menor e a Justiça desnudada}

De menor (2014), filme dirigido pela estreante em longas-metragens Caru Alves de Souza e vencedor do prêmio de Melhor Filme no Festival do Rio

13 Por exemplo Trajetórias de jovens em situação de vulnerabilidade social: sobre a realidade juvenil, violência intersubjetiva e políticas para jovens em Porto Alegre - RS, disponível em: http://bit.ly/2WmO4eu. Acesso em: 15 jun. 2019. 
de $2013^{14}$, tematiza os jovens em conflito com a lei a partir de uma perspectiva bastante particular. Não mais a narração assertiva típica das reportagens e dos programas de televisão sensacionalistas que abordam a violência urbana, mas um modo de narrar lacunar, cheio de elipses, que colocam em dúvida a própria posição do espectador enquanto detentor da verdade. O depoimento da diretora sugere algo nesse sentido: "a sociedade brasileira está julgando muito facilmente, por isso decidi criar situações que o espectador e os personagens não têm total capacidade de julgar. [...] Abri possibilidades de que eles estejam errados" (FERRARI, 2014, s.p.). ${ }^{15}$

No papel de protagonista está Helena (Rita Batata), uma advogada recémformada que trabalha como defensora pública de crianças e adolescentes no Fórum de Santos. Tem como colegas de trabalho o promotor Paulo (Rui Ricardo Diaz), com o qual tem uma relação mais próxima, e o juiz Carlos (Caco Ciocler).

No Fórum, vemos com que frequência ela tem que defender crianças e jovens pobres e negros, fatalmente enquadrados no estereótipo do jovem em conflito com a lei. Há no exercício de sua função algo de maternal: se o promotor e o juiz demonstram-se sempre severos, em tom intimidador, Helena se mostra mais compreensiva, sempre procurando convencer o juiz a considerar atenuantes dos casos e adotar penas mais flexíveis.

Ao mesmo tempo, Helena é irmã do jovem Caio (Giovanni Gallo) e é a responsável legal não só por ele como pela casa em que vivem, uma vez que seus pais vieram a falecer recentemente. Logo nos momentos iniciais do filme, a montagem dá especial ênfase aos momentos de convivência dos irmãos: na praia ou na sala da casa, colocada à venda por problemas financeiros, temos acesso ao cotidiano de proximidade e cumplicidade dos dois, marcado pelo frequente contato físico e por brincadeiras pueris. 

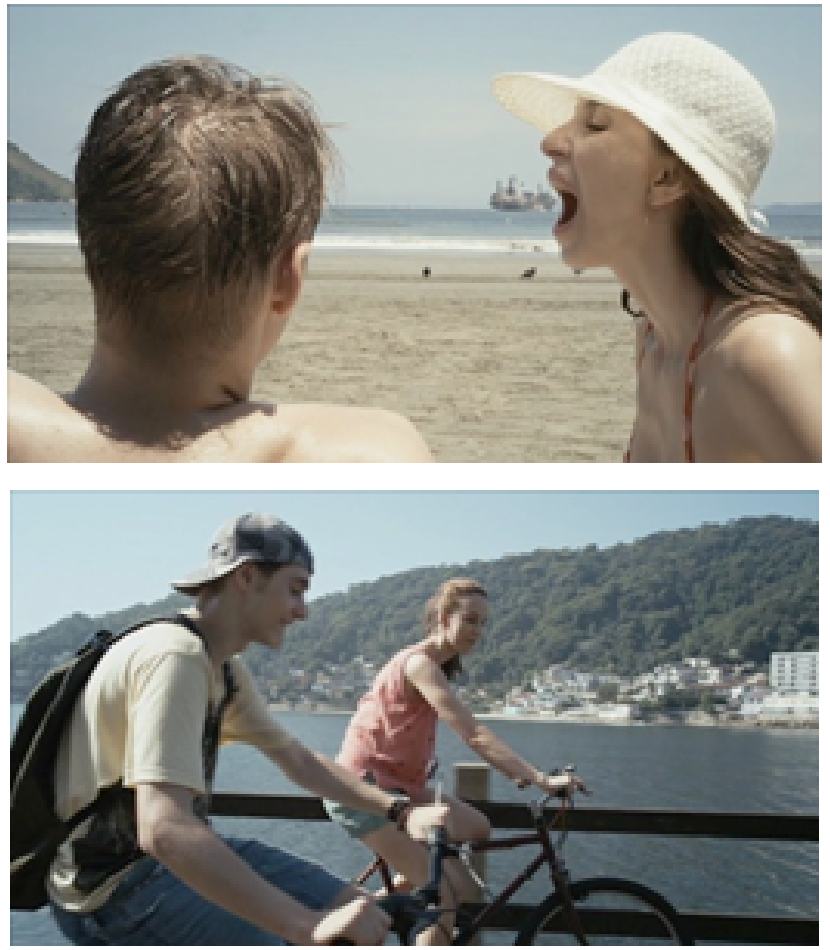

Figuras 1 e 2: alguns dos momentos iniciais da trama, quando vemos a intimidade entre Helena e Caio

Não há, nesse momento, qualquer fato extraordinário: ao contrário, a impressão que se tem é até de uma certa monotonia, resultado também da temperatura elevada - estamos, afinal, em uma cidade litorânea - e do tipo de situação corriqueira abordada.

O filme se divide, assim, entre essas duas facetas da vida de Helena, a profissional e a pessoal. Em ambas, vemos uma mulher jovem, bastante dedicada e comprometida com suas responsabilidades. O tom de proximidade estabelecido com seus colegas de trabalho e com seu irmão mais novo é revelador da dimensão privada, reduzida, de poucos personagens, frequente em outros filmes do cinema brasileiro pós-retomada, como O céu de Suely (Karim Aïnouz, 2006), O som ao redor (Kleber Mendonça Filho, 2012) e Hoje (2011), este último dirigido pela mãe de Caru Alvez de Souza, a cineasta Tata Amaral.

Há nesse aspecto, claramente, uma característica central na narrativa de menor: seu eixo narrativo é construído sempre a partir da perspectiva de Helena. 
Não temos acesso, assim, a situações que fogem do conhecimento ou da participação da personagem.

Assim, percebemos como Helena parece realmente se importar com o destino dos jovens cuja defesa lhe é incumbida, a ponto de ir pessoalmente e sozinha buscar a mãe de um deles. É aí que nos deparamos mais claramente com a pobreza e precariedade flagrantes, a ponto da própria mãe se recusar a acolher o seu filho, única saída para evitar que ele sofresse uma pena mais rígida, simplesmente por não ter condições financeiras de sustentá-lo.

Helena, entretanto, chega a oferecer dinheiro para que a mulher o aceitasse. Aqui percebemos um certo jeitinho, procedimento adotado extraoficialmente e por iniciativa própria de Helena para resolver situações que, de outra maneira, não seriam solucionadas pela Justiça. Após essa primeira parte, em que é revelado - lado pessoal da vida da protagonista, com destaque para sua relação afetiva com seu irmão Caio, a situação entre os dois começa a se deteriorar e vamos acompanhando, sempre pelos olhos de Helena, um jovem que começa a se mostrar gradativamente mais agressivo e impositivo.

Isso acontece, por exemplo, quando Caio passa a pedir dinheiro à irmã com uma certa frequência, intimidando-a, chegando ao ponto de levar sua bolsa sem o seu consentimento. Nunca sabemos a que se destinam esses valores, uma vez que ele se recusa a esclarecê-lo. Como acompanhamos somente os fatos da perspectiva de Helena, não sabemos o que pensa Caio ou quais seus objetivos.

Tudo chega até o ponto em que a vida pessoal e profissional da protagonista se cruzam: no banco do infrator não está mais o jovem pobre e da periferia, mas o seu próprio irmão. Caio aparece algemado, com ferimentos no rosto, cabisbaixo. Não sabemos quais os motivos que o levaram a isso, nem o que exatamente ocorreu. Apenas vemos o que se passa depois: Helena convencendo o promotor a dar um jeitinho e liberá-lo sem comparecer à audiência com o juiz.

O fato, entretanto, volta a se repetir: Caio é encontrado depois de ter infringido a lei - sabemos que se trata do roubo de alguma casa - dessa vez com o agravante de que há a morte por arma de fogo de uma pessoa. Nesse momento, 
entretanto, Helena não pode mais conter os demais procedimentos legais, e o adolescente é levado a julgamento. Enquanto isso, a casa de Helena é saqueada por ladrões, que alegam querer reparar danos causados anteriormente pelo irmão.

Há ainda um outro elemento de importância a ser considerado a respeito de Caio: ele é branco e loiro, fugindo completamente do estereótipo do adolescente em conflito com a lei. Isso é reforçado nesse momento do enredo, quando Helena usa como um dos argumentos para convencer o juiz a probabilidade de que caso Caio fosse internado em uma instituição socioeducativa, pelas características de sua fisionomia, poderia correr o risco de ser violentado ou sofrer represálias de outros internos.

O argumento não funciona e, apesar das tentativas de convencimento tanto por parte da defensora pública como do promotor - que age pela primeira vez em favor do acusado, em claro conflito de interesse por sua proximidade com Helena -, o juiz decide por sua internação provisória, aguardando uma audiência definitiva com a participação de outros envolvidos na infração.

Os fatos se desenrolam até o momento em que Caio se encontra novamente diante do juiz, do promotor e de sua irmã, culminando em sua condenação: ser internado definitivamente em uma instituição socioeducativa. Há, nesse momento da narrativa, novamente uma elipse e não chegamos a ver sequer uma imagem final de despedida entre Helena e Caio: vamos para uma banheira cheia de água, vista de cima, onde a protagonista está nua, imóvel, abraçando-se, como que procurando algum conforto em meio à solidão e à gravidade dos últimos acontecimentos.

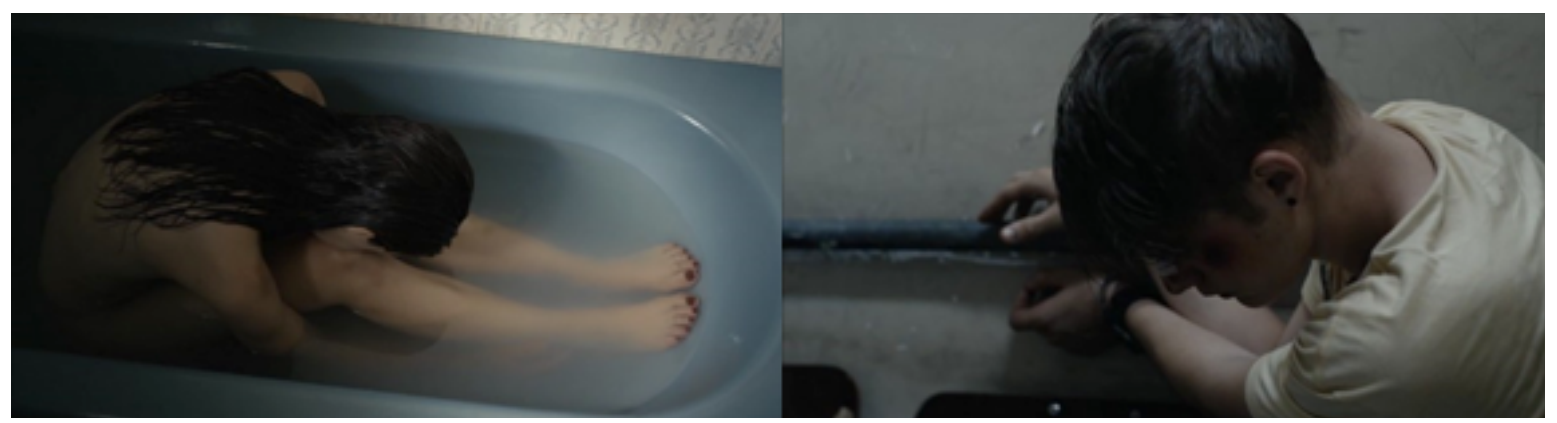

Figuras 3 e 4: momento em que Caio é preso e levado pela segunda vez ao Fórum, seguido pelo plano final do filme, logo após sua condenação 
Como pode ser percebido, há, claramente delineado no enredo, o propósito de contrapor os adolescentes pobres defendidos por Helena com o caso de seu irmão. Esse conflito já aparece na fala da diretora Caru, quando questionada a respeito da condição desses adolescentes no país:

O filme toca sutilmente no tema dos adolescentes ricos e de classe média que cometem infrações. Mesmo esses não são tratados de forma igual pela sociedade. Adolescente pobre e negro que comete infração é bandido, adolescente rico e branco está confuso. ${ }^{16}$ (MESTIERI, 2013, s.p.)

O peculiar, nesse caso, é a maneira como essa distinção é construída na narrativa. Como não temos acesso a todos os acontecimentos que culminam na prisão de Caio, somos obrigados a tirar conclusões baseadas em certas premissas. Como Caio é loiro e branco, contrariando o estereótipo do jovem autor de ato infracional, podemos duvidar em um primeiro momento de sua culpa.

Essa dúvida, entretanto, é colocada em xeque toda vez que Caio é violento com sua irmã. A cada novo sinal de violência ou de atitudes suspeitas, somos confrontados com o estereótipo estabelecido na cultura, no qual jovens pobres e negros seriam os únicos a cometerem infrações a serem punidas.

Dessa forma, entre os diversos discursos que o filme veicula, destaco dois: a possibilidade de que jovens de características físicas divergentes da do estereótipo do jovem em conflito com a lei tenham cometido igualmente infrações; e a promiscuidade que pode existir entre a Justiça e interesses particulares de seus agentes.

\section{O filho dos outros e a cultura juvenil}

O filho dos outros é uma websérie documental de quatro episódios lançada em março de 2017 no YouTube pelo coletivo Rebento. Segundo Bruno Garibaldi ${ }^{17}$, um de seus diretores e idealizadores, a ideia do projeto nasceu em 2015, em reação ao 
envio da PEC 115/2015 18 para a Comissão de Constituição, Justiça e Cidadania (CCJ) do Senado. Diante da falta de material audiovisual a respeito do tema, ele e alguns amigos formaram o coletivo Rebento e apostaram em um outro formato audiovisual:

\begin{abstract}
E a gente foi a princípio pra fazer um vídeo, um vídeo só, sobre a redução. Só que aí a gente começou a pesquisar e cada vez que a gente pesquisava mais a gente via como era complexo e era grande o problema. [...] E aí veio a ideia de fazer a série. Por que a gente percebeu que [...] o trabalho é muito grande, é complexo, fazer um longa-metragem é um produto que às vezes não circula com tanta agilidade...então você precisa talvez ter pequenos vídeos, que as pessoas vejam com mais rapidez, e a gente consegue também serializar os temas dentro da redução. Que era difícil falar da redução em uma narrativa só, não sendo o formato de um longa-metragem. Então pensamos "beleza, a gente separa em episódios, e aborda esses vários núcleos, temas que perpassam a redução".
\end{abstract}

Dos quatro episódios, priorizarei neste artigo o segundo e o quarto, por conta dos pontos convergentes em relação a De menor ${ }^{19}$.

Em Salmo $121^{20}$, segundo episódio da série, o foco da narrativa são os impactos sociais e psicológicos da pena de internação em adolescentes e suas famílias. A narrativa tem início com o depoimento de Raílda Alves, mãe de Daniel, jovem falecido que passou pela Febem. Vestindo a camiseta da Amparar, Associação de Familiares e Amigos de Presos(as), ela diz:

O meu filho, ele deitava na minha cama. Eles dormiam na minha cama, e o meu filho Daniel, ele ficava bem no meu cantinho que eu dormia. Então quando eu chegava de madrugada, ele falava assim "mamãe, você chegou?", "cheguei". Aí ele falava pra mim assim "tá quentinho a sua cama" - porque eu sempre fui meio frienta, e ele sentia muito calor. Seu filho vai pra Febem, seu filho vai pra prisão, independente se ela é mãe, se ela é esposa... ela esquece que ela é mulher, ela não tem mais vaidade, ela não tem mais desejo, ela só vive a vida do filho.

Citada na introdução do artigo.

No primeiro episódio da série, chamado Pea, a equipe foi até o Centro Socioeducativo Dom Bosco, em Fortaleza, e retratou o colapso do sistema socioeducativo no estado do Ceará. No terceiro episódio, Ovelha negra, são entrevistados jovens que cometeram infrações no passado, além de sociólogos e antropólogos estudiosos do tema. 
Ao começar a narrativa desse modo, O filho dos outros já evidencia o objetivo de combater o estigma dos jovens em conflito com a lei: estes são também filhos, namorados, amigos, seres humanos com suas angústias, sonhos e uma cultura que Ihes é peculiar. Não são somente os próprios adolescentes que são impactados pela internação, mas também suas famílias e pessoas mais próximas.

Seguindo essa perspectiva, são articulados os depoimentos de Raílda Alves, de Rafael Primo e Andrea MF, ex-internos da Febem; Erich Montanar, um psicólogo; e Gabriel Feltran, um sociólogo. Aos três primeiros cabe uma fala mais pessoal, calcada na memória, na experiência e em subjetividades atravessadas por medidas de violência e opressão; aos dois últimos cabem falas mais objetivas a respeito dos problemas do sistema socioeducativo, sua similaridade com as prisões e a situação precária de seus funcionários.

Enquanto ouvimos os depoimentos, vemos no campo ${ }^{21}$ imagens da antiga unidade da Febem no bairro Tatuapé, em São Paulo, bem como notícias de jornal, fotografias, áudios retirados de telejornais, imagens de tortura, conferências e eventos culturais. Embora as imagens tenham, pelo próprio teor dos acontecimentos retratados, um certo peso na construção feita pela montagem, no mais das vezes elas servem para confirmar e reforçar o que é dito pelos entrevistados, em uma estrutura que se aproxima do que Bill Nichols (2012, p. 142-143) denomina de modo expositivo: documentários que agrupam "fragmentos do mundo histórico numa estrutura mais retórica ou argumentativa do que estética ou poética", em uma estrutura que depende "muito de uma lógica informativa transmitida verbalmente."

A particularidade, aqui, fica por conta da presença de depoimentos que prezam pela experiência pessoal, mais próximos de outra classificação de Nichols (2012, p. 169), o modo performático: documentários que sublinham "a complexidade de nosso conhecimento do mundo ao enfatizar suas dimensões espaço real no qual vivemos. O espectador, quando assiste a um filme, está diante de um espaço imaginário, também denominado espaço fílmico, que inclui não somente aquilo que se vê, denominado pelo autor de campo, mas também aquilo que não se vê, denominado fora de campo. 
subjetivas e afetivas", entendendo, com isso, que o significado é um fenômeno carregado de afetos e particularidades.

Esses depoimentos, entretanto, são articulados de maneira a constituir uma retórica específica, que culmina na crítica do sistema socioeducativo e das instituições como opressoras e ineficientes na ressocialização dos jovens. Isso fica evidente também no primeiro episódio da série, chamado Pea, no qual é questionada a cultura de encarceramento existente no país: alheios à superlotação das unidades socioeducativas, os juízes insistem em aplicar medidas de restrição de liberdade para jovens que tenham cometido atos infracionais, ignorando outras formas de responsabilização possíveis.

Há em Salmo 121, contudo, algo ainda de particular. Diferentemente do que ocorre em reportagens televisivas que tematizam a violência de jovens, o rosto dos ex-internos é revelado para o espectador, em vez de permanecer anônimo por meio de algum filtro. Embora este por vezes proteja a identidade dos entrevistados, um de seus efeitos mais evidentes é a desumanização daquele que fala, com a exclusão de suas feições próprias e, por vezes, do seu timbre de voz. Sujeitos sem identidade, os entrevistados são profundamente estigmatizados e reduzidos ao próprio delito que cometem, o que é justamente o contrário do que $O$ filho dos outros defende em seu engajamento.
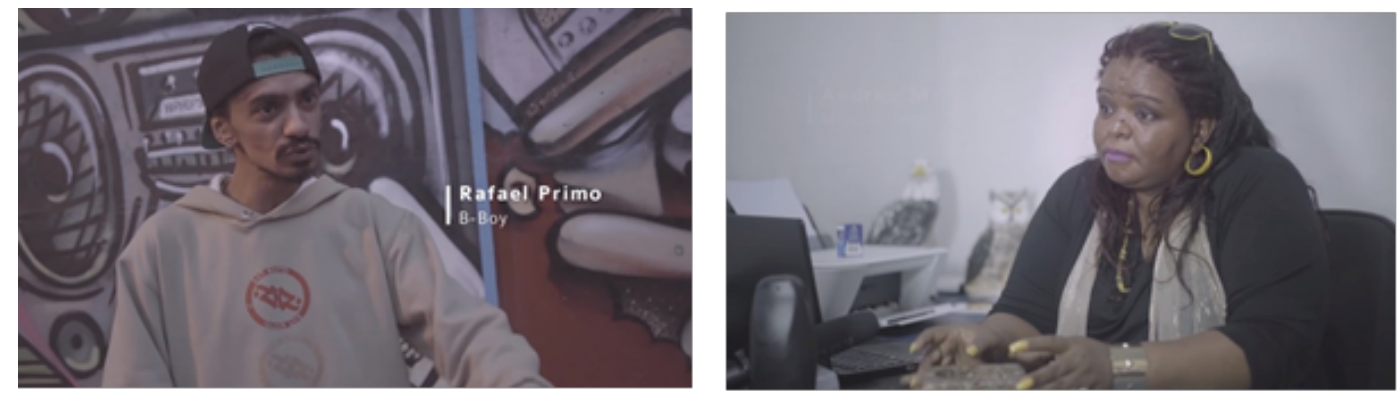

Figuras 5 e 6: depoimentos de Rafael Primo, à esquerda, e de Andrea MF, à direita, em que suas feições são reveladas ao espectador

Esse processo de desconstrução do estigma também se dá na própria caracterização dos entrevistados: no caso de Andrea, o episódio retrata seu lado 
materno e a preocupação que sempre teve com seus pais e filhos; no caso de Rafael, a série registra um momento em que dança na rua, acompanhado de amigos.

Neste último caso, fica evidenciada uma cultura da qual Rafael participa, marcada pela música e pela dança de rua. A inclusão de jovens em movimentos culturais marcados pelo consumo fica evidente ainda no quarto e último episódio da série, Roda Gigante 22 , em que são entrevistados youtubers, MCs e membros de associações.

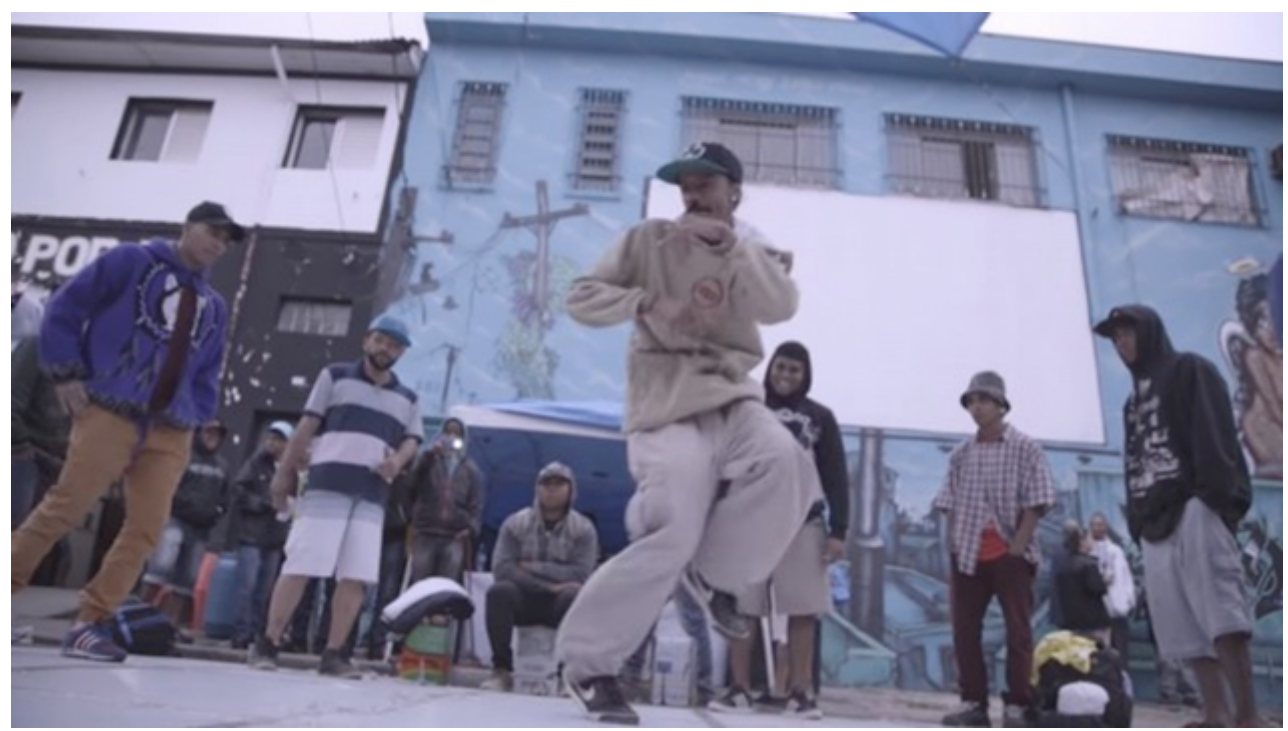

Figura 7: Rafael dançando na rua, acompanhado de outras pessoas

Rolezinhos, funk ostentação e canais do YouTube aparecem nos depoimentos como sinais de uma juventude ávida por reconhecimento social por meio do consumo. Há, entretanto, um estigma que impede tal reconhecimento, revelado por exemplo no depoimento de Renato Barreiros, produtor cultural:

Primeira coisa, jovem de periferia, já por si só o pessoal já tende a criminalizar. Se você por exemplo tem um jovem de classe média alta, e no colégio ele faz uma besteira, ele vai pra uma psicopedagoga, pra uma psicóloga, pra uma orientadora pra entender aquele jovem. O jovem da periferia, se ele faz uma coisinha errada, ninguém chega pra ele e fala "senta aqui, vamos conversar, o que está acontecendo, por que você fez isso..." É tipo "bandido, criminoso". 
Dessa forma, os rolezinhos, encontros de milhares de jovens da periferia em shoppings centers da cidade de São Paulo durante o ano de 2013, foram violentamente reprimidos, por mais que seus integrantes quisessem simplesmente ocupar o papel de consumidores a que tais instituições estão destinadas.

Ao dedicar um episódio para analisar a cultura juvenil, O filho dos outros busca inserir a problemática da infração de adolescentes em um contexto mais amplo, em que o reconhecimento social e o desejo ganham relevo e desconstroem a visão estereotipada e estigmatizada desses jovens.

\section{Considerações finais}

Embora De menor e O filho dos outros sejam de diferentes mídias e gêneros audiovisuais, ambos apresentam certa convergência, no sentido dos discursos que veiculam a respeito da problemática dos jovens em conflito com a lei. Em ambos, encontramos uma crítica à Justiça e às instituições que rodeiam esses adolescentes, seja pela promiscuidade entre interesses públicos e privados (De menor) ou pela precariedade de um sistema que, imerso em uma cultura de encarceramento, reduz parcela da juventude negra e periférica a um estigma de fortes raízes sociais.

Igualmente, aparecem questões de classe e raça, em que jovens brancos de classe média teriam o direito de cometer equívocos, enquanto a jovens negros da periferia caberia somente o rótulo de criminosos. Se, de um lado, De menor enfatiza o contraste existente entre o jovem negro da periferia e o branco de classe média, em uma tensão constante sobre o estereótipo do jovem autor de ato infracional, em $O$ filho dos outros essa diferença se dá na impossibilidade de adolescentes da periferia alcançarem o mesmo reconhecimento social de pessoas da classe média, muito embora se proponham igualmente a consumir dentro de uma lógica capitalista.

Se De menor torna visível a agressividade de Caio, sugerindo com isso a possibilidade de que pessoas longe do estereótipo do jovem em conflito com a lei também cometam infrações, em $O$ filho dos outros é na visibilidade das feições 
de ex-internos, enquadrados nesse estereótipo, que encontramos um recurso de enfrentamento desse estigma.

Em ambos os casos, os jovens que cometem atos infracionais não são somente infratores: em De menor, Caio é um jovem contraditório, que oscila entre o afeto e a agressividade com a irmã; em $O$ filho dos outros, esses jovens também são filhos, pais e pertencem a uma cultura pulsante.

Sabemos como esse estigma, do qual tratam esses discursos, está longe de desaparecer no atual cenário político e social. Meu esforço neste artigo foi o de apresentar dados contextuais, alguns pressupostos teóricos do trabalho e uma breve análise de duas narrativas audiovisuais que apontem para outras possibilidades de representação dessas questões. Mas, além disso, busquei também contribuir de alguma forma para o enfrentamento desse estigma que atravessa a vida de tantos jovens marginalizados e em situação desfavorável na sociedade brasileira.

\section{Referências}

AUMONT, J. A estética do filme. Campinas: Papirus, 1995.

DATAFOLHA: $84 \%$ se dizem a favor da redução da maioridade penal de 18 para 16 anos. G1, Brasília, 14 jan. 2019. Disponível em: https://glo.bo/2ppUttf. Acesso em: 12 jul. 2019.

DYER, R. The role of stereotypes. In: DYER, R. The matter of images. Abingdon: Routledge, 2013

FERRARI, M. Tragédia em tom menor. Pesquisa Fapesp, São Paulo, v. 215, jan. 2014. Disponível em: http://bit.ly/2BTWBfA. Acesso em: 8 jul. 2019. 
FOUCAULT, M. Vigiar e punir: nascimento da prisão. Petrópolis: Vozes, 1987.

GOFFMAN, E. Estigma. Rio de Janeiro: Jorge Zahar, 1978.

GUEDES, A. Redução da maioridade penal gera controvérsias em debate na CCJ. Senado Notícias, Brasília, DF, 27 jun. 2019. Disponível em: http://bit.ly/2JwlIP3. Acesso em: 6 jul. 2019.

INSTITUTO TERRE DES HOMMES BRASIL (org). Manual comunicação e direitos humanos: infância e juventude em pauta. Fortaleza: Instituto Terre des hommes Brasil, 2019.

IPEA - INSTITUTO DE PESQUISA ECONÔMICA APLICADA. Atlas da Violência 2018. Rio de Janeiro, jun. 2018. Disponível em: http://bit.ly/2JwrsmC. Acesso em 14 mar. 2019.

LIPPMANN, W. Opinião Pública. Petrópolis: Vozes, 2017.

LIRA, N. Sobrevivente de ataque em Suzano diz que assassinos checaram se todos tinham morrido: 'Me fingi de morta'. G1, Mogi das Cruzes e Suzano, 13 maio 2019. Disponível em https://glo.bo/2ooiWP8. Acesso em: 13 jul. 2019.

MARINO, A. S. Do infans ao "menor" à concepção de criança e adolescente como sujeitos de direitos. Mnemosine, Rio de Janeiro, v. 9, n. 1, p. 54 -79, 2013.

MAZZARA, B. M. Estereotipos y prejuicios. Madri: Acento Editorial, 1999.

MESTIERI, G. "De Menor" retrata conflitos envolvendo menores em Fórum de Santos. UOL, São Paulo, 29 ago. 2013. Disponível em http://bit.ly/31X8hsk. Acesso em: 11 jul. 2019. 
NICHOLS, B. Introdução ao Documentário. Campinas: Papirus, 2012.

SOARES, R. L. Margens da comunicação: discursos e mídias. São Paulo: Annablume, 2009.

SOUZA, J. A elite do atraso: da escravidão à Lava Jato. Rio de Janeiro: Leya, 2017.

submetido em: 13 jul. 2019 | aprovado em: 5 set. 2019 